then commenced a tirade on my class-told me the clairvoyant knew I was a physician before I came in, and if she could know that, she could know anything else; that the doctors were an ignorant, impudent set of vile pretenders, who took the money out of people's pockets without rendering any service whatever; that they could neither teach nor learn-and were the most abominable pests and nuisances of society. He then demanded a dollar of my friend, which being paid, he abused us both to the door, and slammed the door alter us.

My friend and I congratulated ourselves upon having had so much for a dollar-I saying I should want five for so unuch abuse-he saying tre thought he should hardly like to give it for ten. So much for mesmerism and clairvoyance. J. H. S.

\title{
CASE OF COMPOUND FRACTURE.
}

\section{[Communicated for the Boston Medical nnd Surgicul Joarmal.]}

Since rearling the excelleut address of W. J. Walker, M.D., on compound fiactures, whose opinions on this subject are peculiarly entitled to a favorable reception by the profession, I have thought a case which occurred in my practice, while at Franingham, might not be altogether uninteresting to the readers of the Journal, in cormboration of his views relative to saving limbs which are badly fractured. I have no doubt many limbs, which might have been saved, have been sacrificed to the sturine of ambition by the young surgeon, who may wish the fame of being a good operator. I have noticed, in the vicinity of some surgeons who have the reputation of being good operntors, there are more people who have lost a leg or an arm than in other regions. I will not say that these limbs have been unnecessarily sacrificed; but it proves one of three things, viz., that accidents occur more frequently in those regions, requiring operations of the kind; or that the patients of other surgeons have not recovered; or that limbs have been unnecessarily amputated.

In the month of February, 1843, I was called to see a son of $\mathrm{Na}$ thaniel S. Falkner, of Framingham, aged 6 years. A few minutes before I saw him, he was in the street, when a team was passing with a heavy waggon londed with a cord and a half of green chestnut wood, and, as roguish boys are apt to do, he stepped up behind one of the oxen and struck him. The ox, resenting the blow, kicked the boy immediately before the wheels, both of which passed obliquely across the thighs. The road was composed of hard gravel, and a narrow rut worn down from three to four inches deep. The place of injury of the left thigh was near the middle, and that of the right below the middle, including about one third of the whole length of the thigh. In viewing the limbs sidewise, they appeared about as thick and as flat as the open hand. No pulse could be felt in any part below the place of injury in the right limb. It was cold and livid. In examining the place of injury, I found bone crushed in pieces, the integuments torn through, and the lower fragments had been driven through the pantaloons into the gravel. Sonve of 
the marrow of the bone was found on the pantaloons. The left limb was not so severely injured. Pulsation could be detected in the fook, and the fenoris was broken in two places, corresponding in distance to the width of the wheels. I had no fears but this limb would do well enough, provided there was no other injury. But what was to be done with the other limb. The boy was cold and pulse feeble, evidently in such a state that the shock of the operation of amputation would not be borne well. I therefore decided to place the left limb in as good position as possible, and accordingly dressed it with the many-tailed bandage, and suitable splints, and laid it over a double-inclined plane. I then removed all of the pieces of hone appearing to be loose, and all of the sharp points likely to prick the soft parts, and laid it in nearly a straight position, and enveloped it in cotton to keep it warm, leaving the opening through the integuments in such a position as to allow of the draining of the wound, determining that if, when the boy revived from the first sliock of the accident, circulation and sensation did not return, to amputate. In about six hours the limb became warmer, feeble pulsation could be felt in the ankle, and sensation had partially returned; the leg was less livid.

As the circulation at this time seemed to indicate that the large vessels and nerves were not so injured as to prevent their proper functions buing performed, and relying very much on the previous healthy condition of the boy, and the intelligence of his parents to take suitable care of him, I determined to make an effort to save the limb. There was sufficient discharge of blood from the wound for forty-eight hours to prevent much feser or much inflammation of the part injured. He was gently purged every day during the first week with sulph. mag., and his diet for the first four days, one balf pint of water, and one half of a common cracker per day ; and during the next four days, he was allowed the whole of a cracker prer day, with as much water as he chose to take. After the first eight days he was allowed to take rye mush and milk, and other light food in abundance. On the tenth day the right linib was placed over a double-inclined plane in the same inanner as the other, with the provision of an opening in the board to facilitate the draining of the wound. Abundant suppuration took place, the wound filled up rapilly by granulations, and not a single unfavorable symptom occurred during the whole course of treatment, and in twelve weeks from the dhy of the accident the boy walked to schoo!, a distance of thirty rods, with as good and handsome pair of limbs as any other hoy posserses, with the exception of the right limb being abosut laalf an inch shorter than the left. I make no comments on the case, inerely stating the facts, and shall let others judge as they may as to the correciness of the practice.

Charlesioun, Jan. 13, 1847.

Otrs Hoyt, M.D.

\section{H.PIDEMIC; ICTERUS.}

To the Elito: of the Boston Medical and Surgical Journal.

Sin,-In your Journal of January 13, I saw a notice, by Dr. Bmwn, of Wiluington, Mls., of an epidemic which is prevailing on the Merrimac 